\section{Concentrated Exogenous Abscisic Acid Drenches Reduce Root Hydraulic Conductance and Cause Wilting in Tomato}

\author{
Manuel G. Astacio ${ }^{1}$ and Marc W. van Iersel \\ Department of Horticulture, The University of Georgia, 1111 Miller Plant \\ Sciences Building, Athens, GA 30602
}

Additional index words. ABA, photosynthesis, stomates, stomatal conductance, transpiration

\begin{abstract}
Previous work has shown that exogenous abscisic acid (ABA) applications can reduce transpiration, delay wilting, and thereby extend the shelf life of unwatered plants. Paradoxically, we have seen that drenches with concentrated ABA solutions may actually induce wilting. These wilting symptoms occur despite the presence of ample water in the substrate, suggesting that ABA may interfere with the ability of roots to take up water. Our objective was to develop a better understanding of this wilting effect using tomato (Solanum lycopersicum) as a model. In the first study, ABA drenches $\left(125-2000 \mathrm{mg} \cdot \mathrm{L}^{-1}\right)$ reduced transpiration and water use compared with the control plants, yet the relative water content (RWC) of the leaves of ABA-treated plants was lower than that of control plants at $24 \mathrm{~h}$ after the ABA drench. Control plants had a leaf RWC of 97\%, whereas plants treated ABA had a RWC of $57 \%$ to $62 \%$. ABA concentrations of $500 \mathrm{mg} \cdot \mathrm{L}^{-1}$ or higher caused the plants to wilt within $24 \mathrm{~h}$ despite the presence of ample water in the substrate. Leaf $A B A$ concentrations $24 \mathrm{~h}$ after the $A B A$ application ranged from 2.6 (control) to $62.6 \mathrm{nmol} \cdot \mathrm{g}^{-1}$ fresh weight $(\mathrm{FW})$ in the $2000-\mathrm{mg} \cdot \mathrm{L}^{-1} \mathrm{ABA}$ treatment, indicating effective transport of $A B A$ from the roots to the leaves. The reduced leaf $R W C$ suggests that $A B A$ drenches are limiting water transport through the roots to the leaves. The effects of $A B A$ on the hydraulic conductance of the roots and stems of tomatoes were quantified to determine if ABA drenches limit water transport through the roots. The cumulative volume of water conducted by the root systems during a 4-day period ranged from $36.7 \mathrm{~mL}$ in the control treatments to $8.1 \mathrm{~mL}$ in roots systems drenched with $1000 \mathrm{mg} \cdot \mathrm{L}^{-1} \mathrm{ABA}$, a reduction of $78 \%$. When the conductance study was repeated using decapitated roots and excised stems, root water flux was again reduced by $A B A$, but water flux through internodal stem sections did not show an ABA effect. Results suggest that $A B A$-induced wilting is caused by a reduction in root conductance and we hypothesize that $\mathrm{ABA}$ affects aquaporins in the roots, limiting water uptake.
\end{abstract}

A common problem in garden centers is that the plants awaiting sale may not receive enough water. Inadequate watering can cause wilting and diminishes a plant's salability and drastically shortens its shelf life (Armitage, 1983). Researchers have been looking for ways to reduce transpiration and thereby potentially reduce maintenance costs while increasing the shelf life of plants. As a result of a breakthrough in microfermentation production, ABA has recently become a commercially feasible growth regulator (Runkle, 2009). ABA has been found to be a part of a myriad of plant developmental and physiological processes, including acclimation to drought and other stresses. ABA is produced in response to drought, and its concentration in the leaves is negatively correlated with

Received for publication 24 Aug. 2011. Accepted for publication 6 Oct. 2011.

We thank Valent BioSciences Corp. for their financial support and Fafard, Inc. for donation of the substrate. Technical help was provided by Sue Dove.

${ }^{1}$ To whom reprint requests should be addressed; e-maildmc12@uga.edu. stomatal aperture (Mahdieh and Mostajeran, 2009; Walton, 1980), thus limiting water lost as a result of transpiration (Franks and Farquhar, 2001; Jiang and Hartung, 2008). Once a drought-stressed plant is watered, the leaf concentration of ABA rapidly decreases and stomatal conductance $\left(g_{\mathrm{S}}\right)$ returns to its pre-stress state (Franks and Farquhar, 2001).

ABA may extend the shelf life of plants by slowing water consumption. Sprenches (spraying and allowing the excess spray to runoff into the substrate) with $250 \mathrm{mg} \cdot \mathrm{L}^{-1}$ ABA solution extended the shelf life of various bedding plant species by 1 (Verbena $\times$ hybrida) to almost $6 \mathrm{~d}$ (Impatiens hawkeri) (Blanchard et al., 2007). Drenches with ABA solutions also effectively reduced water use of salvia (Salvia splendens; Kim and van Iersel, 2011), hydrangea (Hydrangea macrophylla; van Iersel et al., 2009), and tomato (Astacio and van Iersel, 2011) and extended the shelf life of the plants in a dose-dependent manner. The optimal application method may be speciesspecific, because Waterland et al. (2010a) reported that some species seem to respond more to sprays and other species are more affected by drenches. Undesirable side effects such as chlorosis and leaf abscission may occur when high concentrations of ABA are applied (Blanchard et al., 2007; Kim and van Iersel, 2011; Waterland et al., 2010b). Another side effect is that ABA drenches may induce wilting, even if the plants are well watered (Barrett et al., 2009). The cause of this ABAinduced wilting is not understood, but it does not appear to occur when ABA is applied as a spray (Barrett and Bartuska, 2011). However, similar symptoms occur in tomato in response to flooding, which decreases both leaf and root hydraulic conductance with root water flux decreasing to $50 \%$ of the pre-stress level within $8 \mathrm{~h}$ (Bradford and Hsiao, 1982). Bradford and Hsiao (1982) concluded that stomatal closure, along with petiole epinasty, is a flooding response used to maintain leaf water potential. They also concluded that ABA may be responsible for the observed stomatal closure, and Hiron and Wright (1973) reported that leaves of flooded tomato plants experienced a six- to eightfold increase in ABA content. Anaerobic root conditions appeared to induce this ABA accumulation in leaves, although the precise mechanism was not clear (Bradford and Hsiao, 1982).

The conclusions of past studies on the relationship between root conductance and ABA are at times contradictory. Exogenous ABA injection applications $\left(13-53 \mathrm{mg} \cdot \mathrm{L}^{-1}\right)$ into a pressure chamber diminished conductance of decapitated soybean (Glycine $\max$ L.) root systems over the course of 3-4 h (Markhart et al., 1979). However, other findings suggest that $\mathrm{ABA}$ increases root conductance. Ion and solution exudation rates of excised sunflower (Helianthus annuus L.) root systems increased when the roots were transferred to $1 \mathrm{mg} \cdot \mathrm{L}^{-1}$ ABA solution and the increased solute flux into the roots elevated the osmotic flow of water (Glinka, 1980). Hose et al. (2000) examined excised root cells of maize (Zea mays L.) with pressure probes and concluded that 0.01-1 $\mathrm{mg} \cdot \mathrm{L}^{-1} \mathrm{ABA}$ transiently increased hydraulic conductance of root cells for a few hours by stimulating the opening of water channels (aquaporins) in the cell membranes. Conversely, $20 \mathrm{mg} \cdot \mathrm{L}^{-1} \mathrm{ABA}$ impacted the root systems of common bean (Phaseolus vulgaris) seedlings in four ways; it increased volume flux, stimulated a pulsed release of solutes into the xylem, which led to a gradual increase in solute flux, but there was a decline in root conductance after several hours had passed (Fiscus, 1981). This corroborates the findings of Markhart et al. (1979), who determined that $\mathrm{ABA}$ limits root hydraulic conductance, thereby protecting the membranes from cold stress damage.

A more recent study (Mahdieh and Mostajeran, 2009) showed that tobacco (Nicotiana tabacum) plants exposed to 0.26 $\mathrm{mg} \cdot \mathrm{L}^{-1}$ ABA applied in a hydroponic nutrient solution increased root and cell conductance compared with control plants within $24 \mathrm{~h}$. These plants also showed increased expression of genes involved in the development of plasma membrane intrinsic protein (PIP)-type aquaporins, suggesting that ABA activates and regulates the production of aquaporin 
water channels (Mahdieh and Mostajeran, 2009). One common factor among the studies that concluded that ABA increases root conductance is that the increase was transient, lasting only a few hours after ABA treatment. It is possible that $\mathrm{ABA}$ temporarily increases water uptake through its impact on aquaporins and then limits it by causing morphological changes to the roots (i.e., suberization) as a means of protecting the plant from drought stress. Zhang et al. (1995) found that maize seedlings (Zea mays) long exposed to drought conditions can return to pre-drought hydraulic conditions within a few days after rewatering. A flush of new root growth aided in the observed increase in conductance. A short-term increase in root conductance was also noted in both briefly and mildly droughted maize seedlings (Zhang et al., 1995), which may be the result of ABA temporarily increasing conductance before limiting it. Presently, the effects of $\mathrm{ABA}$ on the roots are unresolved and future studies will need to fully elucidate the impact that ABA has on water transport channels in the cell membranes and overall root conductance both in the short- and long-term.

The objectives of our studies were to examine the effects of ABA drenches on the leaf physiology of tomato and to determine the effects of ABA on root and stem conductance to better understand the previously observed ABA-induced wilting. We also wanted to quantify the effect of ABA drenches on leaf ABA concentrations, because none of the recent studies looking at $\mathrm{ABA}$ and shelf life extension quantified how much ABA actually reaches the leaves. Tomatoes were used as the model crop because they are sensitive to ABA applications (Sharma et al., 2006) and wilt rapidly when exposed to high ABA concentrations, although ample water is present in the substrate.

\section{Materials and Methods}

Leaf physiological responses. 'Supersweet 100 ' tomatoes were seeded in 72-cell trays in a glass greenhouse and were grown on an $\mathrm{ebb}$ and flow bench providing a $100 \mathrm{mg} \cdot \mathrm{L}^{-1}$ nitrogen solution of a complete fertilizer (15-5-15 Cal-Mag; Scotts, Marysville, OH; $15 \mathrm{~N}-2.2 \mathrm{P}-12.45 \mathrm{~K})$ for $14 \mathrm{~d}$ after germination. Seedlings were transplanted on 28 Feb. 2011 into $15-\mathrm{cm}$ diameter round pots filled with soilless substrate (Fafard 1P; Conrad Fafard Inc., Agawam, MA) and then grown under an overhead irrigation system. The plants each received $11.7 \mathrm{~g}$ of controlled-release fertilizer (14-14-14 Osmocote; Scotts; 14N-6.2P$11.6 \mathrm{~K})$. The tomatoes were transferred to a growth chamber (E-15; Conviron, Winnipeg, Manitoba, Canada) on 10 Mar. 2011 and given $3 \mathrm{~d}$ to acclimate to the conditions, during which time they were hand-watered. The growth chamber was set to $12 \mathrm{~h}$ days at $25^{\circ} \mathrm{C}$ with a photosynthetic photon flux of 405 $\mu \mathrm{mol} \cdot \mathrm{m}^{-2} \cdot \mathrm{s}^{-1}$ (daily light integral $=17.5$ $\mathrm{mol} \cdot \mathrm{m}^{-2} \cdot \mathrm{d}^{-1}$ ) and $12 \mathrm{~h}$ nights at $21^{\circ} \mathrm{C}$. At the start of the experiment, the pots were placed inside plastic bags sealed around the stems of the plants to prevent evaporation from the substrate. The weights of the plants were measured every $10 \mathrm{~min}$ with load cells (LSP-1 and LSP-2; Transducer Techniques, Temecula, CA) connected to a data logger (CR10; Campbell Scientific, Logan, UT) to determine cumulative transpiration as determined from the weight loss from the pot and plant.

An ABA stock solution ( $10 \% \mathrm{w} / \mathrm{v}$ s-ABA, the biologically active form of ABA, VBC30101; Valent BioSciences, Long Grove, IL) was diluted with deionized water to yield concentrations of $0,125,250,500,1000$, and $2000 \mathrm{mg} \cdot \mathrm{L}^{-1}$ ABA. This range of concentrations was chosen based on our prior knowledge that high ABA concentrations induced wilting in tomatoes. Drench applications of $150 \mathrm{~mL}$ of ABA solutions were made on 13 Mar. 2011 and symptoms of ABA-induced wilting were noted within $24 \mathrm{~h}$ of application. At this time, measurements of leaf net photosynthesis $\left(\mathrm{P}_{\mathrm{n}}\right)$, transpiration $(\mathrm{E})$, and $g_{\mathrm{S}}$ were taken with a portable gas exchange system (CIRAS-2; PP Systems, Amesbury, MA) on the uppermost fully expanded leaf of each plant. Substrate water content (SWC) was measured using a soil moisture sensor (Theta Probe ML2x; Delta-T Devices, Burwell, Cambridge, U.K.). Leaf relative water content data were taken by sampling 12 leaf discs from the uppermost, fully expanded leaves of each of the treatment groups (three discs $\times$ four replications per ABA treatment rate). Leaf discs were weighed initially to determine FW. They were then placed in a petri dish with deionized water overnight to establish a turgid weight (TW) after which the discs were dried at $75^{\circ} \mathrm{C}$ for $1 \mathrm{~d}$ to determine dry weight (DW). Relative water content was calculated as RWC $=[(\mathrm{FW}-$ $\mathrm{DW}) /(\mathrm{TW}-\mathrm{DW})] \times 100 \%$.

Fresh leaf samples were collected from each plant at $24 \mathrm{~h}$ after the ABA application and immediately frozen in liquid nitrogen to be used for ABA quantification using an enzymelinked immunosorbent assay (ELISA) kit (PDK 09347; Agdia, Elkhart, IN). Leaf samples were kept at $-80{ }^{\circ} \mathrm{C}$ until the assay was completed. The ELISA assay was done according to the protocol from Serrano et al. (1995) with minor adjustments. The samples were ground into a powder under liquid nitrogen and $0.75 \mathrm{~g}$ of ground leaf tissue was mixed with $15 \mathrm{~mL}$ of extraction buffer $(80 \%$ methanol). Samples were then incubated for $16 \mathrm{~h}$ on a shaker at $4{ }^{\circ} \mathrm{C}$, centrifuged, and supernatant was collected and stored at $-20^{\circ} \mathrm{C}$ to be used in the assay. Because of the high ABA concentrations, the samples were further diluted with tris(hydroxymethyl)aminomethanebuffered saline solution to $1: 100,1: 1,000$, and 1:10,000 ratios. Controls were diluted to a ratio of $1: 100$. ABA concentrations were then quantified using ELISA following the manufacturer's instructions. Leaf ABA concentrations were expressed on a FW basis.

The experimental design was a randomized complete block with four replications and six concentrations of ABA. The experimental unit was an individual plant. The load cell data were analyzed using regression (SAS 9.2; SAS Institute, Cary, NC). Because hormonal effects on plant physiology are generally not directly proportional to the hormonal concentration, $\mathrm{ABA}$ concentrations were transformed using $\log ([\mathrm{ABA}]+50)$ before testing for linear and quadratic effects of ABA concentration, and significance was analyzed separately for 10-min intervals of data. Data for E, $g_{\mathrm{s}}, \mathrm{P}_{\mathrm{n}}$, SWC, and RWC were analyzed using analysis of variance followed by mean separation using Fisher's protected least significant difference. Leaf ABA concentrations were $\log _{10}$ transformed to meet the assumption of equal variance before fitting a hyperbolic equation.

Root and stem hydraulic conductance. Two studies examined the impact of ABA drenches on conductance. For the first study, 'Supersweet 100 ' tomatoes were seeded in 72-cell trays on 27 Jan. 2010 and grown in a glass greenhouse. After germination, plants were transplanted into $10-\mathrm{cm}$ diameter round pots filled with soilless substrate (Fafard 2P; Conrad Fafard Inc.). At the time of transplanting, each plant received $3.1 \mathrm{~g}$ controlled-release fertilizer (14-14-14 Osmocote; Scotts; 14N$6.2 \mathrm{P}-11.6 \mathrm{~K})$ and the plants were watered daily. The ABA stock solution $(10 \% \mathrm{w} / \mathrm{v}$ s-ABA, VBC-30101; Valent BioSciences) was diluted with deionized water to yield concentrations of $0,62.5,125,250,500$, and $1000 \mathrm{mg} \cdot \mathrm{L}^{-1}$.

At the start of the experiment $(17 \mathrm{Feb}$. 2010; $21 \mathrm{~d}$ after seeding), plants were placed inside a laboratory at a temperature of $\approx 20^{\circ} \mathrm{C}$. The shoots were cut off below the first node, and the remaining portions of the shoots were then inserted into plastic tubing (Bev-a-Line IV; ThermoPlastic Processes, Georgetown, DE; internal diameter $6.3 \mathrm{~mm}$ ). The stems were sealed to the inside of the tubes with a silicone gel (3140 RTV coating; Dow Corning, Midland, MI) and the stem/tube connection was sealed with parafilm to prevent leaks. All tubes were connected to a manifold, which was connected to a vacuum pump (MOAP122-AA; Gast Mfg. Corp., Benton Harbor, $\mathrm{MI)}$ to simulate transpirational pull with an approximate suction of $14 \mathrm{kPa}$. Water levels in the tubes were marked daily for the duration of the study, and these readings and the tubing diameter were used to calculate the cumulative water flow through the root systems. These data were then used to calculate the rate of flow. Once the vacuum pump was turned on, initial readings of water flux were taken for $3 \mathrm{~h}$ before ABA application to determine an untreated conductance baseline. The ABA solutions were applied as $50-\mathrm{mL}$ drenches.

The experiment was designed as a randomized complete block with four replications and six ABA concentrations. The experimental unit was an individual plant. The study was ended $9 \mathrm{~d}$ after ABA application, at which time root conductance in all treatments was minimal. ABA concentrations were transformed using $\log ([\mathrm{ABA}]+50)$ before testing for linear and quadratic effects of $\mathrm{ABA}$ on root hydraulic conductance. The data were analyzed using linear and quadratic regression in the SAS program (SAS 9.2; SAS Institute).

For the second study, 'Supersweet 100' tomatoes were seeded in 72-cell trays on 8 June 2010 and grown in a glass greenhouse. After germination, plants were transplanted 
into $10-\mathrm{cm}$ diameter round pots filled with soilless substrate (Fafard 2P; Conrad Fafard Inc.) and grown under an overhead irrigation system for $21 \mathrm{~d}$. The plants each received $2.6 \mathrm{~g}$ controlled-release fertilizer (14-14-14 Osmocote; Scotts; $14 \mathrm{~N}-6.2 \mathrm{P}-11.6 \mathrm{~K})$. At the start of the experiment (6 July 2010), the pots were well-watered. Shoots were cut off $\approx 5-6 \mathrm{~cm}$ above the substrate surface, and 4-cm long, internodal stem sections with a diameter of $\approx 0.75 \mathrm{~cm}$ were cut from the shoots. The stem sections and root systems were then sealed into plastic tube manifold as described previously and the tubes were connected to a vacuum pump. The bases of the stem sections were placed in beakers with $100 \mathrm{~mL}$ deionized water.

Once the pump was turned on (providing a suction of $14 \mathrm{kPa}$ ), initial readings of water movement through the root systems and stem sections were taken for $3 \mathrm{~h}$ before ABA application to determine an untreated conductance baseline. ABA solutions were prepared as described previously. All treatment applications to the root systems were made as a $100-\mathrm{mL}$ drench of either ABA solution or deionized water (control). For the stem sections, the deionized water in the beakers was replaced with either $100 \mathrm{~mL}$ of ABA solution or fresh deionized water (control). The water levels in the tubes were marked at various times and were used to determine the cumulative water flow through the roots or stems by measuring distance the water had traveled inside the tube and multiplying by the volume of the tube $(1 \mathrm{~cm}=0.69 \mathrm{~mL})$. At the end of the study, the root systems were washed off and visually examined for any detrimental side effects caused by ABA.

The experimental design was a randomized complete block with a split plot with two replications. The main treatment factor was the ABA concentration (six rates) and the split consisted of root systems vs. stem sections. Individual root systems or stem sections were the experimental unit. The study was conducted twice, and both trials returned similar results. Data were analyzed using regression analysis (SAS 9.2; SAS Institute).

\section{Results and Discussion}

Leaf physiological responses. One day after treatment with the highest doses of ABA (500-2000 $\left.\mathrm{mg} \cdot \mathrm{L}^{-1}\right)$, the plants wilted, whereas control plants and plants treated with lower concentrations of ABA (125-250 $\left.\mathrm{mg} \cdot \mathrm{L}^{-1}\right)$ appeared turgid. At $60 \mathrm{~min}$, cumulative transpiration was highest in the lowest ABA concentration (control treatment, $P<$ 0.01; Fig. 1), and this continued for the remainder of the study. These findings are consistent with our previous work, which showed that ABA drenches result in rapid reductions in cumulative evapotranspiration of tomato (Astacio and van Iersel, 2011). Boldt (2008) found that chrysanthemum (Chrysanthemum $\times$ morifolium) roots can take up enough $\mathrm{ABA}$ within a $7.5-\mathrm{min}$ period to induce stomatal closure. At $28 \mathrm{~h}$ post-ABA application, the control plants maintained the highest transpiration rate, culminating in $\approx 317 \mathrm{~mL}$ cumulative transpiration since treatments were applied. By this time, the plants treated with $125 \mathrm{mg} \cdot \mathrm{L}^{-1} \mathrm{ABA}$ had transpired $\approx 95.1 \mathrm{~mL}$, a reduction of $70 \%$, and those treated with $2000 \mathrm{mg} \cdot \mathrm{L}^{-1} \mathrm{ABA}$ treatment had transpired $40 \mathrm{~mL}$, a reduction of $87 \%$ compared with the control plants (Fig. 1).

Leaf gas exchange measurements were consistent with the whole plant transpiration results. At the end of the experiment, control plants had a $g_{\mathrm{s}}$ of $127 \mathrm{mmol} \cdot \mathrm{m}^{-2} \cdot \mathrm{s}^{-1}$ compared with $18 \mathrm{mmol} \cdot \mathrm{m}^{-2} \cdot \mathrm{s}^{-1}$ for the $2000-\mathrm{mg} \cdot \mathrm{L}^{-1}$ ABA treatments ( $86 \%$ reduction), and $\mathrm{ABA}$ treatment effects on $\mathrm{E}$ were similar (Table 1). Thus, ABA effectively limited transpirational water loss. We have previously shown that ABA drenches cause stomatal closure and reduced $\mathrm{E}$ within $1 \mathrm{~h}$ of application (Astacio and van Iersel, 2011). As a result of the reduced $\mathrm{E}$, the substrate water content after $24 \mathrm{~h}$ tended to increase with increasing ABA concentration, but this was not significant (Table 1). These substrate water content data show that the ABA-induced wilt is not related to a lack of water in the substrate because the substrate water contents were all similar, but only plants treated with $500-2000 \mathrm{mg} \cdot \mathrm{L}^{-1}$ ABA wilted. The substrate water content data also show that the plants were not exposed to extreme flooding conditions and that the observed reductions in transpiration were not related to a flooding response. All ABA concentrations also reduced $P_{n}$. Control plants had a $\mathrm{P}_{\mathrm{n}}$ of $4.26 \mu \mathrm{mol} \cdot \mathrm{m}^{-2} \cdot \mathrm{s}^{-1}$ compared with $-2.13 \mu \mathrm{mol} \cdot \mathrm{m}^{-2} \cdot \mathrm{s}^{-1}$ for the $2000-\mathrm{mg} \cdot \mathrm{L}^{-1} \mathrm{ABA}$ treatment (Table 1). Relative water content of the leaves was also reduced by ABA applications; control leaves had a RWC of $97 \%$, whereas ABA-treated plants had a RWC of $57 \%$ to $62 \%$ (Table 1 ).

ABA concentrations in the leaves increased as the ABA dose increased (Fig. 2). Control plants had an ABA concentration of $2.57 \mathrm{nmol} \cdot \mathrm{g}^{-1} \mathrm{FW}$, which was slightly higher than previously reported endogenous ABA levels for unstressed tomatoes (0.49 to 2.4 $\mathrm{nmol} \cdot \mathrm{g}^{-1} \mathrm{FW}$; Neill and Horgan, 1985; Sharp et al., 2000; Thompson et al., 2007). The ABA concentrations in ABA-treated plants ranged from $12.5\left(125 \mathrm{mg} \cdot \mathrm{L}^{-1} \mathrm{ABA}\right)$ to $62.6 \mathrm{nmol} \cdot \mathrm{g}^{-1}$ FW (2000 $\left.\mathrm{mg} \cdot \mathrm{L}^{-1} \mathrm{ABA}\right), 24 \times$ higher than that in the control plants (Fig. 2). The higher concentration ABA treatments resulted in leaf ABA concentrations that are higher than most previously reported, stress-induced endogenous ABA levels. Thompson et al. (2007) reported a $2 \times$ increase in ABA concentration to $3.6 \mathrm{nmol} \cdot \mathrm{g}^{-1} \mathrm{FW}$, whereas Neill and Horgan (1985) reported an ABA concentration of

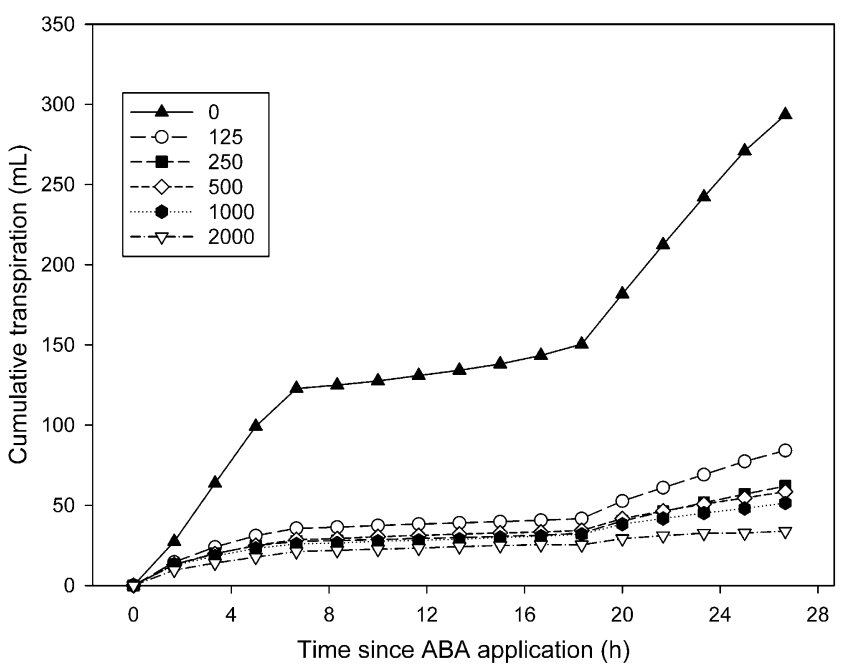

Fig. 1. Cumulative transpiration of tomato plants over a $28-\mathrm{h}$ period after treatment with abscisic acid (ABA) drenches. Significant effects of ABA on cumulative transpiration were noted starting 60 min after the ABA application and lasted the duration of the study $(P<0.01)$. Linear effects of $\log ([\mathrm{ABA}]+50)$ on transpiration were observed after $60 \mathrm{~min}$ and quadratic effects from $70 \mathrm{~min}$ and beyond $(P<0.05)$.

Table 1. Substrate water content and leaf physiological parameters of tomatoes in response to drenches with abscisic acid (ABA) solutions. ${ }^{\mathrm{z}}$

\begin{tabular}{cccccc}
\hline $\begin{array}{l}\text { ABA concn } \\
\left(\mathrm{mg} \cdot \mathrm{L}^{-1}\right)\end{array}$ & $\begin{array}{c}\text { Substrate water } \\
\text { content }\left(\mathrm{m}^{3} \cdot \mathrm{m}^{-3}\right)\end{array}$ & $\begin{array}{c}\text { Photosynthesis } \\
\left(\mu \mathrm{mol} \cdot \mathrm{m}^{-2} \cdot \mathrm{s}^{-1}\right)\end{array}$ & $\begin{array}{c}\text { Transpiration } \\
\left(\mathrm{mmol} \cdot \mathrm{m}^{-2} \cdot \mathrm{s}^{-1}\right)\end{array}$ & $\begin{array}{c}\text { Stomatal conductance } \\
\left(\mathrm{mmol} \cdot \mathrm{m}^{-2} \cdot \mathrm{s}^{-1}\right)\end{array}$ & $\begin{array}{c}\text { Relative water } \\
\text { content }(\%)\end{array}$ \\
\hline 0 & $0.27 \mathrm{a}^{\mathrm{y}}$ & $4.26 \mathrm{a}$ & $1.62 \mathrm{a}$ & $127 \mathrm{a}$ & $97 \mathrm{a}$ \\
125 & $0.25 \mathrm{a}$ & $0.68 \mathrm{~b}$ & $0.63 \mathrm{~b}$ & $57 \mathrm{~b}$ & $57 \mathrm{~b}$ \\
250 & $0.32 \mathrm{a}$ & $0.75 \mathrm{~b}$ & $0.46 \mathrm{~b}$ & $37 \mathrm{~b}$ & $60 \mathrm{~b}$ \\
500 & $0.28 \mathrm{a}$ & $-2.38 \mathrm{c}$ & $0.64 \mathrm{~b}$ & $51 \mathrm{~b}$ & $58 \mathrm{~b}$ \\
1000 & $0.30 \mathrm{a}$ & $-0.71 \mathrm{bc}$ & $0.22 \mathrm{~b}$ & $17 \mathrm{~b}$ & $62 \mathrm{~b}$ \\
2000 & $0.31 \mathrm{a}$ & $-2.13 \mathrm{bc}$ & $0.23 \mathrm{~b}$ & $18 \mathrm{~b}$ & $60 \mathrm{~b}$ \\
\hline
\end{tabular}

${ }^{\mathrm{z}}$ Measurements were taken $\approx 24 \mathrm{~h}$ after ABA application. Leaf gas exchange: $\mathrm{n}=4$, relative water content $(\mathrm{n}=2)$.

${ }^{\mathrm{y}}$ Means followed by the same letter are not significantly different from each other. 


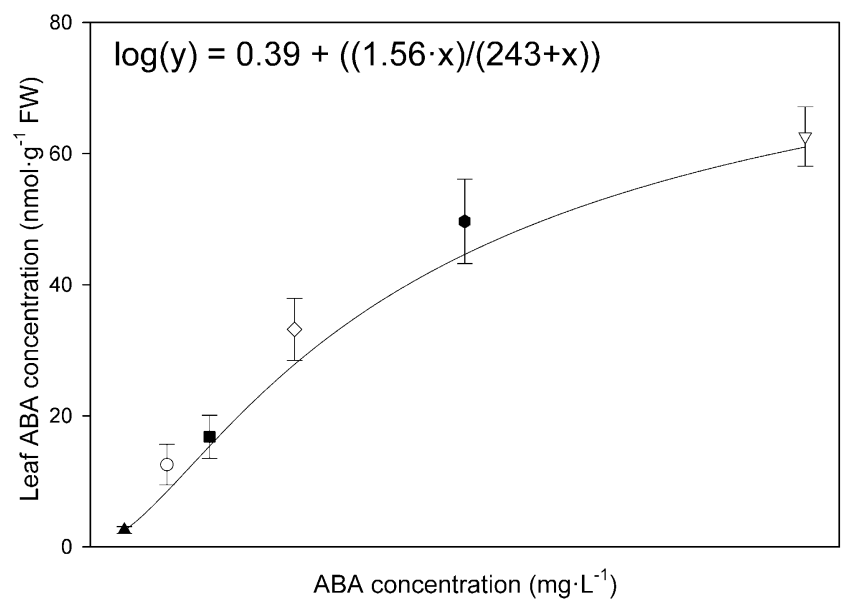

Fig. 2. Abscisic acid (ABA) concentration in leaves of tomatoes treated with ABA drenches, expressed per unit fresh weight (FW). ABA treatments were made $28 \mathrm{~h}$ before leaf sampling. Data represent the averages of four repetitions $\pm \mathrm{SE}\left(R^{2}=0.81, P<0.0001\right)$.

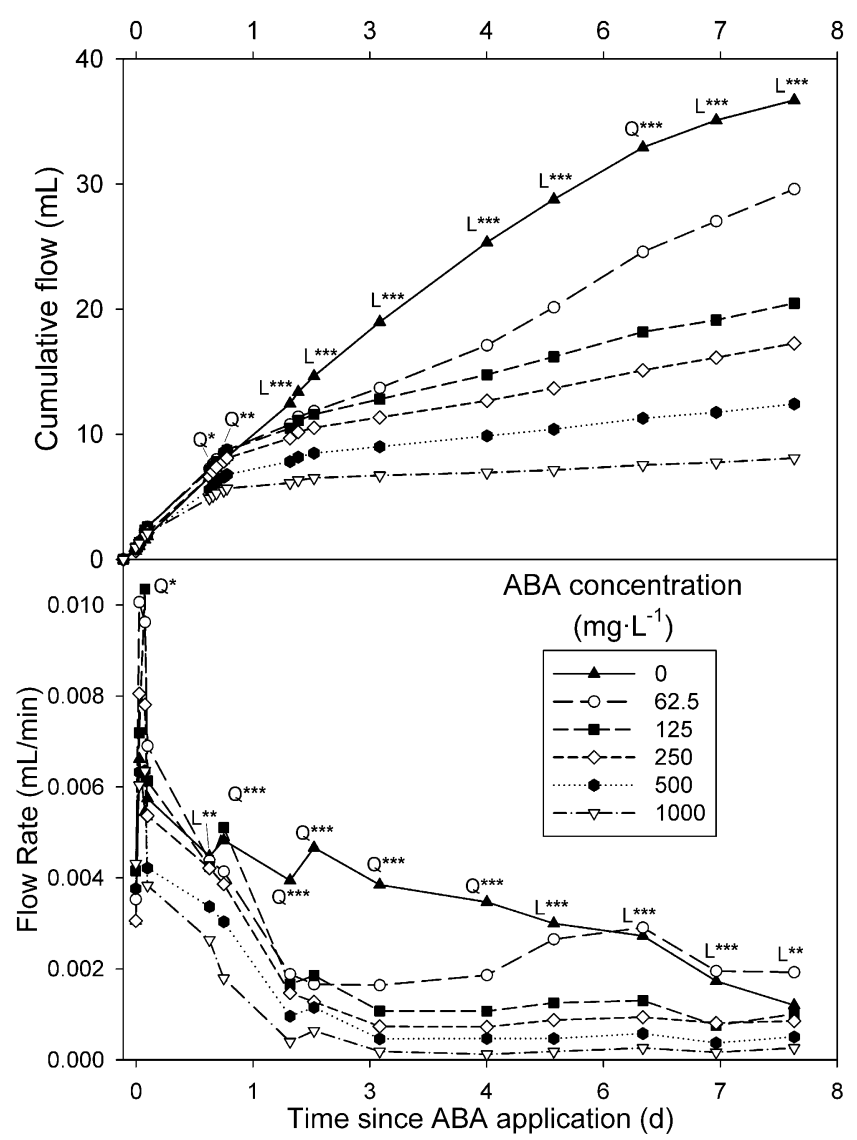

Fig. 3. Cumulative flow and rate of flow through decapitated root systems of tomato as affected by drenches containing differing concentrations of abscisic acid (ABA). ABA was applied at time $0\left({ }^{*} P<\right.$ $\left.0.05,{ }^{* *} P<0.01,{ }^{* * *} P<0.001\right) ; \mathrm{L}=$ linear, $\mathrm{Q}=$ quadratic effects of $\log ([\mathrm{ABA}]+50)$.

$15 \mathrm{nmol} \cdot \mathrm{g}^{-1} \mathrm{FW}$, or $10 \times$ increase, in droughtstressed tomato. Water-stressed tomatoes have shown increases from two to $22 \times$ the unstressed ABA levels, although typically reported increases fall within the 10-15x range (Bray, 1988; Neill and Horgan, 1985; Thompson et al., 2007). A 10-15× increase would be roughly comparable to the concentrations seen in our 250 and $500-\mathrm{mg} \cdot \mathrm{L}^{-1} \mathrm{ABA}$ treatments (Fig. 2). Reported increases of endogenous $\mathrm{ABA}$ in tomatoes resulting from other stresses vary, ranging from 1.5 to $3 \times$ in response to cold stress (Daie and Campbell, 1981) and salt stress eliciting a $2 \times$ increase in ABA concentrations (Chen and Plant, 1999).

We found that application of ABA quickly and effectively closed stomata and limited transpirational water loss. Despite the plants all having similar substrate water contents and ABA-treated plants exhibiting decreases in transpiration, the RWC of leaves from ABAtreated plants was lower than in control plants. In combination with reduced transpiration, the low RWC in the leaves suggests an impairment of water transport through the roots to the leaves, which could have caused the ABAinduced wilt.

Root and stem hydraulic conductance. Pre-treatment measurements of water flow through the root systems showed no differences among the plants in the first study (Fig. 3). ABA drenches quickly reduced water flow through the root systems. Roughly $2-3 \mathrm{~h}$ post-ABA application, a dosage-dependent decrease in flow rate through the roots in response to the ABA treatments was evident $(P<0.05$; Fig. 3 , bottom). This translated into a decrease in cumulative root flow for ABAtreated plants within $1 \mathrm{~d}$ after ABA application $(P<0.001$; Fig. 3, top). These differences persisted for both flow rate and cumulative flow for the remainder of the study. Root flow rates decreased in all treatments during the first $3 \mathrm{~d}$, and this was most pronounced in ABA-treated plants (Fig. 3). By the termination of the experiment, control plants had a flow rate of $1.7 \mu \mathrm{L} / \mathrm{min}$, whereas plants treated with $1000 \mathrm{mg} \cdot \mathrm{L}^{-1}$ had a flow rate of $0.25 \mu \mathrm{L} / \mathrm{min}$, a reduction of $85 \%$ (Fig. 3). No sloughing or necrosis of ABA-treated roots was visible at the termination of the study.

The results are consistent with our hypothesis that reductions in the hydraulic conductance of the roots in response to ABA may cause the ABA-induced wilting. Our results corroborate earlier findings that root hydraulic conductance is reduced by $\mathrm{ABA}$ treatment (Davies et al., 1982; Fiscus, 1981; Markhart et al., 1979). Other studies, however, have reported that $\mathrm{ABA}$ treatments increase root hydraulic conductance. Glinka (1977) found that treating decapitated root systems of sunflower with $1 \mathrm{mg} \cdot \mathrm{L}^{-1} \mathrm{ABA}$ resulted in a higher exudation rate and proposed that $\mathrm{ABA}$ is affecting the water permeability of the root endodermal layer. Glinka (1980) conducted further work with ABA on sunflower root systems and reported that treating the roots with $1 \mathrm{mg} \cdot \mathrm{L}^{-1}$ ABA solution increased flux of $\mathrm{K}^{+}$and $\mathrm{NO}_{3}{ }^{-}$ions into the xylem as well as increasing the hydraulic conductance of the roots. Cornish and Zeevaart (1985) conducted studies exposing tomato roots to drought stress and found that endogenous ABA accumulated in the roots, and it was concluded that the plant may accumulate ABA to modify its water use before the leaves experienced wilting. Secondary hardening of roots in response to drought stress was noted by Cornish and Zeevaart (1985) but was not substantial, although their work measured endogenous ABA and did not use concentrated exogenous ABA applications like we did. During cold acclimation, changing levels of ABA also seem to affect root conductance. When soybean roots were treated with $13 \mathrm{mg} \cdot \mathrm{L}^{-1} \mathrm{ABA}$ and subsequently exposed to $10{ }^{\circ} \mathrm{C}$, root hydraulic conductance was higher in $\mathrm{ABA}$-treated plants than control plants and ABA helped to mitigate cold stress damage (Markhart, 1984). This increase in root hydraulic conductance 
in response to ABA treatment and cold stress was rapid (within $4 \mathrm{~h}$ ) and similar to the transient increases seen in conductance of wheat roots when chilled and treated with ABA (Davies et al., 1982).

ABA can affect symplastic water transport pathways such as aquaporins, thereby regulating transpiration (Hose et al., 2000; Mahdieh and Mostajeran, 2009). ABA has a role in aquaporin regulation in intact tobacco plants and increases root hydraulic conductance by stimulating the expression of genes that control the development of PIP-type aquaporins, suggesting that ABA regulates the production of these water channels (Mahdieh and Mostajeran, 2009). Endogenous ABA may interact with these channels during periods of drought stress, and root water flux may be coordinated with $g_{\mathrm{S}}$ through aquaporin activity (Tyerman et al., 2002). Wan et al. (2004) concluded that ABA can potentially increase transcellular water flow by gating aquaporin channels and preventing them from collapsing. This agrees with the suggestion that ABA may be responsible for the transient increases in water flux through maize root cells by regulating aquaporins (Hose et al., 2000). Recent studies have confirmed that regulation of aquaporin abundance and aquaporin-related genes is indeed associated with changes in root hydraulic conductance in hybrid poplar (Populus trichocarpa $\times$ deltoides) (AlmeidaRodriguez et al., 2011) and Melaleuca argentea (McLean et al., 2011). It has been suggested that aquaporin abundance in the roots may be regulated by the transpirational demand of the shoots (Sakurai-Ishikawa et al., 2011). This would explain why ABA drenches, which reduce $g_{\mathrm{s}}$, and thus transpirational demand, may reduce hydraulic conductance of the roots. Aquaporin involvement may also explain how ABA, by altering membrane permeability, increases water flux during periods of cold stress (Markhart, 1984), a finding reported well before the first detailed description of aquaporins (Agre et al., 1993). This area of study requires further research to fully understand the signaling pathway between $\mathrm{ABA}$ and aquaporin channels and to determine how much of an effect aquaporins can have on overall root water flux.

An important point to consider in interpreting our results is that past studies either worked with endogenous ABA or applied $\mathrm{ABA}$ at much lower concentrations than the rates used in our studies. Applying large amounts of ABA to roots may elicit different responses than the results seen after a gradual build-up of endogenous ABA in response to drought or cold.

Root conductance data from our second study were similar to the first study with significant reductions in root conductance within $12 \mathrm{~h}$ after ABA application (results not shown). At the termination of the experiment, the cumulative flow through roots of the control plants was $27.4 \mathrm{~mL}$, whereas the cumulative flow of plants treated with $1000 \mathrm{mg} \cdot \mathrm{L}^{-1} \mathrm{ABA}$ was only $4.8 \mathrm{~mL}$, a reduction of $83 \%$. There were no visible symptoms of ABA-induced side effects on the appearance of the roots.
Unlike the root systems, water flow through the stem sections was unaffected by the ABA treatments. Cumulative water flow through the stem sections was between 29.6 and $36.5 \mathrm{~mL}$ with no trend of an ABA-related effect (results not shown). However, the flow rate through the stems decreased rapidly after the first day. This suggests that the deionized water used in the treatments may have had detrimental effects on the functionality of the stem xylem, which may have masked any potential effects of ABA. Thus, future research looking at conductance of stem sections may need to be done using a solution that mimics xylem sap rather than deionized water.

Our findings may also be relevant to the long-distance, root to shoot signaling under drought as described by Christmann et al. (2007). This hydraulic, long-distance signal can induce ABA production in the leaves and thus cause stomatal closure. The hydraulic signal could simply be the result of soil drying, which reduces root water uptake and xylem pressure, thus attenuating a hydraulic signal to the leaves. However, our results suggest that $\mathrm{ABA}$ in the roots could play a role in this hydraulic signaling: if drought-induced ABA production reduces root conductance, this would result in a larger drop in xylem flux and pressure than soil drying alone. Therefore, the decrease in root conductance in response to ABA may serve a physiological role in strengthening this hydraulic signal to the shoots and thus aid in stomatal closure as drought stress develops.

\section{Conclusions}

Exogenous ABA drenches quickly reduced transpiration of tomatoes. However, despite reduced transpiration, the leaves of ABA-treated plants $\left(500-2000 \mathrm{mg} \cdot \mathrm{L}^{-1}\right)$ wilted. There was a corresponding reduction in RWC in response to the ABA treatments. We also demonstrated that ABA levels in the leaves rise dramatically after drenches with ABA. These results suggest that the ABAinduced wilt may be an effect of unnaturally high ABA concentrations applied as drenches to the roots. Root systems quickly showed an ABA-induced reduction in water flux. This suggests that ABA causes reductions in root conductance, which hinders water transport to the shoots and leads to the observed drops in leaf relative water content and the ABAinduced leaf wilt.

\section{Literature Cited}

Agre, P., G.M. Preston, B.L. Smith, J.S. Jung, S. Raina, C. Moon, W.B. Guggino, and S. Nielsen. 1993. Aquaporin CHIP: The archetypal molecular water channel. Amer. J. Physiol. 265:F463-F476.

Almeida-Rodriguez, A.M., U.G. Hacke, and J. Laur. 2011. Influence of evaporative demand on aquaporin expression and root hydraulics of hybrid poplar. Plant Cell Environ. 34:1318-1331.

Armitage, A.M. 1983. Keeping quality of bedding plants. Florists' Review 171:63-66.

Astacio, M.G. and M.W. van Iersel. 2011. Determining the effects of abscisic acid drenches on evapotranspiration and leaf gas exchange of tomato. HortScience 46:1512-1517.
Barrett, J.E. and C.A. Bartuska. 2011. s-ABA delays wilting in petunia and impatiens. Acta Hort. 893:1271-1276.

Barrett, J.E., C.A. Bartuska, and D.G. Clark. 2009 Effects of s-ABA on ethylene insensitive petunias. Proc. Plant Growth Reg. Soc. Amer. 36:104.

Blanchard, M.G., L.A. Newton, E.S. Runkle, and D. Woolard. 2007. Exogenous applications of abscisic acid improved the postharvest drought tolerance of several annual bedding plants. Acta Hort. 755:127-132.

Boldt, J.L. 2008. Whole plant response of chrysanthemum to paclobutrazol, chlormequat chloride, and (s)-abscisic acid as a function of exposure time using a split-root system. MS thesis, Univ. of Florida, Gainesville, FL.

Bradford, K.J. and T.C. Hsiao. 1982. Stomatal behavior and water relations of waterlogged tomato plants. Plant Physiol. 70:1508-1513.

Bray, E.A. 1988. Drought- and ABA-induced changes in polypeptide and mRNA accumulation in tomato leaves. Plant Physiol. 88: $1210-1214$

Chen, C.C.S. and A.L. Plant. 1999. Salt-induced protein synthesis in tomato roots: The role of ABA. J. Expt. Bot. 50:677-687.

Christmann, A., E.W. Weiler, E. Steudle, and E. Grill. 2007. A hydraulic signal in root-to-shoot signaling of water shortage. Plant J. 52:167-174.

Cornish, K. and J.A.D. Zeevaart. 1985. Abscisic acid accumulation by roots of Xanthium strumariam L. and Lycopersicon esculentum Mill. in relation to water stress. Plant Physiol. 79:653-658.

Daie, J. and W.F. Campbell. 1981. Response of tomato plants to stressful temperatures. Plant Physiol. 67:26-29.

Davies, W.J., J.L. Rodriguez, and E.L. Fiscus. 1982. Stomatal behavior and water movement through roots of wheat plants treated with abscisic acid. Plant Cell Environ. 5:485-493.

Fiscus, E.L. 1981. Effects of abscisic acid on the hydraulic conductance of and the total ion transport through Phaseolus root systems. Plant Physiol. 68:169-174.

Franks, P.J. and G.D. Farquhar. 2001. The effects of exogenous abscisic acid on stomatal development, stomatal mechanics, and leaf gas exchange in Tradescantia virginiana. Plant Physiol. 125:935-942.

Glinka, Z. 1977. Effects of abscisic acid and of hydrostatic pressure gradient on water movement through excised sunflower roots. Plant Physiol. 59:933-935.

Glinka, Z. 1980. Abscisic acid promotes both volume flow and ion release to the xylem in sunflower roots. Plant Physiol. 65:537-540.

Hiron, R.W.P. and S.T.C. Wright. 1973. The role of endogenous abscisic acid in the response of plants to stress. J. Expt. Bot. 24:769-781.

Hose, E., E. Steudle, and W. Hartung. 2000. Abscisic acid and hydraulic conductivity of maize roots: A study using cell- and root-pressure probes. Planta 211:874-882.

Jiang, F. and W. Hartung. 2008. Long-distance signaling of abscisic acid (ABA): The factors regulating the intensity of the ABA signal. J. Expt. Bot. 59:37-43.

Kim, J. and M.W. van Iersel. 2011. ABA drenches induce stomatal closure and prolong shelf life of Salvia splendens. Sci. Hort. 127:420-423.

Mahdieh, M. and A. Mostajeran. 2009. Abscisic acid regulates root hydraulic conductance via aquaporin expression modulation in Nicotiana tabacum. J. Plant Physiol. 166:1993-2003.

Markhart, A.H. 1984. Amelioration of chillinginduced water stress by abscisic acid-induced changes in root hydraulic conductance. Plant Physiol. 74:81-83. 
Markhart, A.H., E.L. Fiscus, A.W. Naylor, and P.J. Kramer. 1979. Effect of abscisic acid on root hydraulic conductivity. Plant Physiol. 64:611-614.

McLean, E.H., M. Ludwig, and P.F. Grierson. 2011. Root hydraulic conductance and aquaporin abundance respond rapidly to partial root-zone drying events in a riparian Melaleuca species. New Phytol 192:664-675.

Neill, S.J. and R. Horgan. 1985. Abscisic acid production and water relations in wilty tomato mutants subjected to water deficiency. J. Expt. Bot. 36:1222-1231.

Runkle, S.E. 2009. ABA coming to floriculture. Greenhouse Product News 19:42.

Sakurai-Ishikawa, J., M. Murai-Hatano, H. Hayashi, A. Ahamed, K. Fukushi, T. Matsumoto, and Y. Kitagawa. 2011. Transpiration from shoots triggers diurnal changes in root aquaporin expression. Plant Cell Environ. 34:1150-1163.

Serrano, M., M.C. Martínez-Madrid, F. Riquelme, and F. Romojaro. 1995. Endogenous levels of polyamines and abscisic acid in pepper fruits during growth and ripening. Physiol. Plant. 95:73-76.
Sharma, N., S.R. Abrams, and D.R. Waterer. 2006. Evaluation of abscisic acid analogs as holding agents in bedding plant seedlings. HortTechnology 16:71-76.

Sharp, R.E., M.E. LeNoble, M.A. Else, E.T. Thorne, and F. Gherardi. 2000. Endogenous ABA maintains shoot growth in tomato independently of effects on plant water balance: Evidence for an interaction with ethylene. J. Expt. Bot. 51:15751584.

Thompson, A.J., J. Andrews, B.J. Mulholland, J.M.T. McKee, H.W. Hilton, J.S. Horridge, G.D. Farquhar, R.C. Smeeton, I.R.A. Smillie, C.R. Black, and I.B. Taylor. 2007. Overproduction of abscisic acid in tomato increased transpiration and root hydraulic conductivity and influences leaf expansion. Plant Physiol. 143:1905-1917.

Tyerman, S.D., C.M. Niemietz, and H. Bramley. 2002. Plant aquaporins: Multifunctional water and solute channels with expanding roles. Plant Cell Environ. 25:173-194.

van Iersel, M.W., K. Seader, and S. Dove. 2009. Exogenous abscisic acid application effects on stomatal closure, water use, and shelf life of hydrangea (Hydrangea macrophylla). J. Environ. Hort. 27:234-238.

Walton, D.C. 1980. Biochemistry and physiology of abscisic acid. Annu. Rev. Plant Physiol. 31:453-489.

Wan, X.C., E. Steudle, and W. Hartung. 2004. Gating of water channels (aquaporins) in cortical cells of young corn roots by mechanical stimuli (pressure pulses): Effects of ABA and $\mathrm{HgCl}_{2}$. J. Expt. Bot. 55:411-422.

Waterland, N.L., C.A. Campbell, J.J. Finer, and M.L. Jones. 2010a. Abscisic acid application enhances drought stress tolerance in bedding plants. HortScience 45:409-413.

Waterland, N.L., J.J. Finer, and M.L. Jones. 2010b. Benzyladenine and gibberellic acid application prevents abscisic acid-induced leaf chlorosis in pansy and viola. HortScience 45: 925-933.

Zhang, J., X. Zhang, and J. Liang. 1995. Exudation rate and hydraulic conductivity of maize roots are enhanced by soil drying and abscisic acid treatment. New Phytol. 131:329-336. 